\title{
SYSTEM TESTOWANIA ODPORNOŚCI DOKUMENTÓW NA DWUSTRONNE ZGINANIE
}

\begin{abstract}
System służy do sprawdzania odporności dokumentów z wbudowanym zabezpieczeniem w postaci układu RFID na wielokrotne naprzemienne dwustronne zginanie. Za jego pomoca jest realizowana metoda testowa zalecana przez Międzynarodową Organizację Lotnictwa Cywilnego (ICAO). Badanie powoduje przyspieszone zużycie zmęczeniowe, głównie w obszarze, w którym znajduje się antena układu RFID i jej połączenia. Do realizacji testu są wykorzystywane dwa specjalne urządzenia: przyrząd kalibrujący do wyznaczania strzałki ugięcia badanego dokumentu pod działaniem obciążenia równego $40 \mathrm{~N}$ oraz tester do realizacji określonej liczby cykli zginających. Są one wyposażone w układy pomiaru strzałki ugięcia badanego dokumentu, regulację ugięcia i programowalny licznik cykli. Badany dokument jest zamocowany jedną krawędzią w uchwycie obrotowym, a przeciwległa krawędź znajduje się pomiędzy rolkami podtrzymującymi. Rolki zginające przemieszczają się w obie strony tak, że zginają cały dokument, symulując obciążenia występujące podczas użytkowania. Plan testu ICAO przewiduje wykonanie 1000 cykli obustronnego przegięcia, a następnie kontrolę działania układu RFID. W celu umożliwienia badania dokumentów o różnym formacie i sztywności przewidziano zmianę parametrów geometrycznych i dynamicznych urządzeń testujących. Są one dostosowane do różnych wymiarów dokumentów, konstrukcji, sztywności i miejsca umieszczenia zabezpieczenia elektronicznego. Metoda testowania odporności na wielokrotne naprzemienne dwustronne zginanie może być również stosowana do badania innych wyrobów poddawanych w trakcie użytkowania podobnym obciążeniom, np. różnego rodzaju połączeń klejonych, wyrobów wielowarstwowych, laminatów czy powłok ochronnych.
\end{abstract}

Słowa kluczowe: RFID, trwałość dokumentów, zginanie dwustronne, test trwałościowy

\section{Wprowadzenie}

Różnorodność negatywnych czynników oddziałujących na dokumenty osobiste w czasie ich użytkowania stanowi podstawę do definiowania niezbędnych

${ }^{1}$ Stanisław Kozioł, Instytut Technologii Eksploatacji - Państwowy Instytut Badawczy, ul. Pułaskiego 6/10, 26-600 Radom

2 Autor do korespondencji/corresponding author: Andrzej Zbrowski, Instytut Technologii Eksploatacji - Państwowy Instytut Badawczy, ul. Pułaskiego 6/10, 26-600 Radom tel.: (48) 3649243, fax: (48) 3644760, e-mail: andrzej.zbrowski@itee.radom.pl 
metod testowania trwałości i odporności na fałszowanie, podrabianie, dokonywanie nieautoryzowanych zmian w zapisanych danych [1-3]. System testowania powinien kompleksowo uwzględniać następujące elementy:

- standardowe metody wywierania określonych oddziaływań symulujących obciążenia użytkowe o zdefiniowanych parametrach, takich jak siła oddziaływania, odkształcenie, czas działania, częstotliwość, miejsce oddziaływania itp.,

- standardowe metody sprawdzania wpływu oddziaływań użytkowych na możliwość odczytu danych zawartych w dokumencie metodą optyczną i elektroniczna, na wytrzymałość i kształt dokumentu, trwałość barw itp.,

- procedury testowania określające sekwencje wywierania obciążeń na badane obiekty i sposób oceny ich skutków oraz kryteria oceny,

- plany badań określające liczbę dokumentów poddawanych badaniom, zastosowanie odpowiednich procedur badawczych w zależności od celu badań i rodzaju badanych dokumentów.

Przykładem takiego systemu jest testowanie paszportów przystosowanych do automatycznego odczytu danych, wdrożone przez ICAO [4, 5], w którym zostały zdefiniowane następujące elementy:

- 15 metod wywierania wymuszeń imitujących oddziaływania użytkowe,

- 6 metod sprawdzania wpływu tych wymuszeń na stan techniczny dokumentu i możliwość odczytu zawartych w nim danych,

- 14 procedur testowania odpowiadających różnego rodzaju obciążeniom użytkowym możliwym do wystapienia podczas eksploatacji.

Jedną z metod badania trwałości dokumentów przyjętych przez ICAO jest testowanie odporności na wielokrotne dwustronne naprzemienne zginanie. Metoda powoduje przyspieszone zużycie zmęczeniowe przez wymuszone odkształcenie, głównie w obszarze, w którym znajduje się antena układu RFID i jej połączenia. Badany dokument (zazwyczaj paszport) jest zamocowany w uchwycie obrotowym stroną grzbietową lub krótszą krawędzią książeczki tak, że jego dolna część znajduje się pomiędzy rolkami podtrzymującymi (rys. 1.).

Rolki zginające umieszczone w odległości H2 od uchwytu obrotowego zależnej od pozycji dokumentu i jego formatu przemieszczają się poziomo w obie strony (tak jak to pokazano na rys. 1b) i zginają cały dokument. Przesunięcie $b$ rolek odpowiada założonej sile zginającej dokument lub określonej strzałce ugięcia. Plan testu określa liczbę cykli obustronnego przegięcia oraz amplitudę odkształcenia. Wielokrotne poprzeczne zginanie badanego dokumentu może być realizowane w dwóch pozycjach: równolegle do dłuższego i krótszego boku. W Instytucie Technologii Eksploatacji PIB w Radomiu zostały opracowane i wykonane dwa specjalne urządzenia niezbędne do realizacji testu: przyrząd kalibrujący do wyznaczania strzałki ugięcia badanego dokumentu pod działaniem obciążenia równego $40 \mathrm{~N}$ oraz tester do realizacji określonej liczby cykli zginających [6]. 
a)

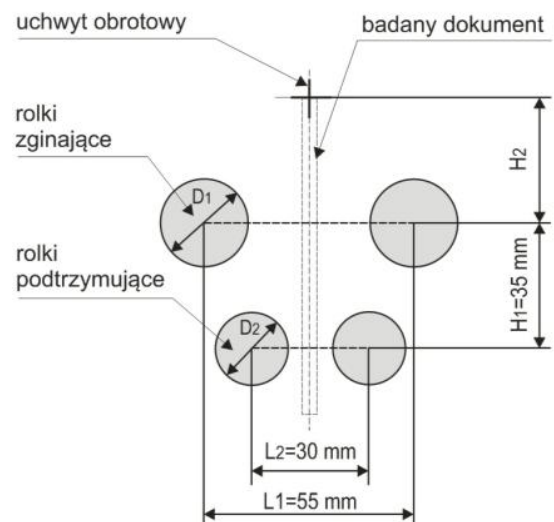

b)

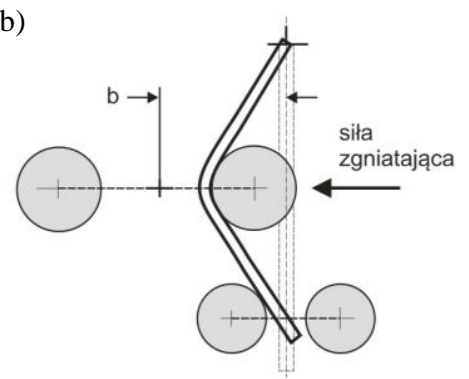

Rys. 1. Schemat testu dynamicznego naprzemiennego zginania paszportu: a) geometria układu testowego, b) sposób obciążenia dokumentu

Fig. 1. Diagram of the test of the dynamic alternating bending of a passport: a) geometry of the testing system, b) a way of document load

\section{Przyrząd kalibracyjny do wyznaczania ugięcia dokumentu}

Przyrząd kalibracyjny, którego wirtualny model przedstawiono w postaci wydruku na rys. 2., służy do wyznaczania strzałki ugięcia dokumentu pod działaniem określonej siły. Jest on urządzeniem mechanicznym, wykorzystującym grawitacyjny system zadawania obciążenia. Stanowi instrumentarium uzupełniające, niezbędne do wyznaczenia parametrów testu określającego odporność dokumentów na wielokrotne, cykliczne, dwustronne zginanie. Wszystkie mechanizmy przyrządu są zabudowane w korpusie wykonanym ze standardowych profili aluminiowych. Testowany dokument jest mocowany w uchwycie tak, aby znajdował się pomiędzy pojedynczymi rolkami ruchomymi i stałymi. Zgodnie $\mathrm{z}$ procedurą badania odległość $\mathrm{H} 2$ ustawia się (rys. 1.) pomiędzy uchwytem i osiami rolek ruchomych za pomocą tarczy regulacyjnej. Przesunięcie rolek ruchomych (zginających) w prawo powoduje zazębienie zaczepu i zatrzasku oraz uniesienie obciążnika. Śruba pociagowa służy do wykonania precyzyjnych ruchów ustawczych pomiędzy rolkami a dokumentem zamocowanym w uchwycie obrotowym. Zderzak odchylny i listwa zderzaka ograniczają skok układu do wartości odpowiadającej maksymalnemu dopuszczalnemu ugięciu dokumentu równemu $20 \mathrm{~mm}$. Wskaźnik rolek ruchomych pokazuje na skali wartość przesunięcia ustawczego (bez obciążenia) oraz wartość ugięcia próbki pod wpływem siły ciężkości obciążnika. Sumaryczna wartość tych wielkości stanowi parametr wejściowy drugiej części testu przeprowadzanego za pomocą urządzenia przeznaczonego do realizacji cykli zginających. Na fotografii (rys. 3.) przedstawiono prototyp przyrządu kalibrującego. 

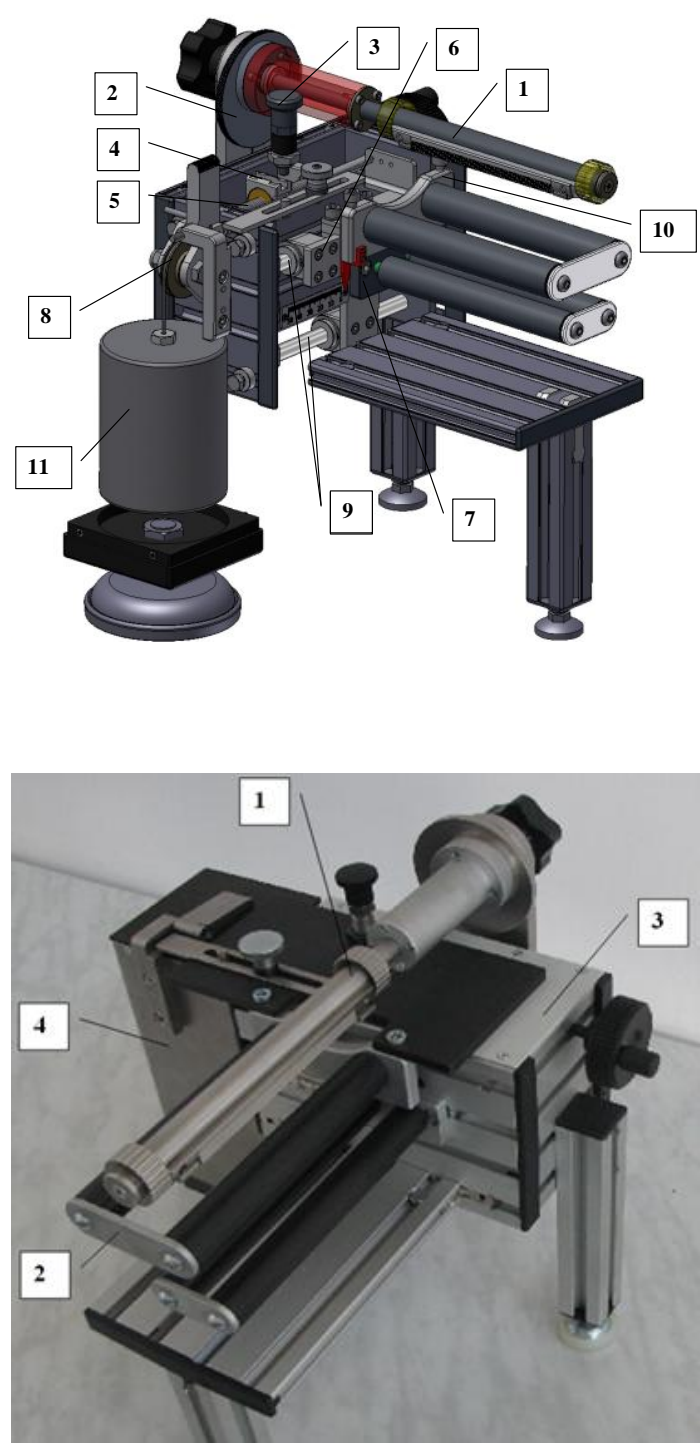

Rys. 2. Model przyrządu kalibrującego do wyznaczania strzałki ugięcia dokumentu (widok bez osłon): 1 - uchwyt dokumentu, 2 - tarcza regulacji położenia uchwytu, 3 - zatrzask, 4 - zaczep zatrzasku, 5 - śruba pociagowa zatrzasku, 6 - suwak, 7 - mocowanie rolek stałych, 8 - linka obciążnika, 9 - prowadnice toczne, 10 - mocowanie rolek ruchomych do suwaka, 11 - obciążnik

Fig. 2. The model of a calibrating instrument for the determination of a document deflection value (view without covers): 1 - document grip, 2 - grip positioning disc, 3 - latch, 4 - latch fastener, 5 - lead-screw of a latch, $6-$ slide, 7 - permanent roller binding, 8 weight cable, 9 - rolling guides, $10-$ moveable roller adjustment to the slide, 11 - weight

Rys. 3. Prototypowy przyrząd kalibracyjny do wyznaczania strzałki ugięcia dokumentu: 1 - moduł uchwytu obrotowego, 2 - zespół rolek zginających, 3 - korpus, 4 - moduł obciążnika

Fig. 3. Prototype calibrating instrument for the determination of the document deflection value: 1 - rotational grip module, 2 - unit of bending rollers, 3 body, 4 - weight module

\section{Tester do badania odporności na dwustronne zginanie}

Tester jest przeznaczony do realizacji określonej liczby cykli dwustronnego zginania badanego dokumentu z zastosowaniem parametrów wyznaczonych za pomocą urządzenia kalibrującego. W układzie kinematycznym urządzania zastosowano mechanizmy mimośrodowe, korbowodowe i suwakowe (rys. 4.). Urządzenie służy do jednoczesnego badania sześciu dokumentów. Jego budowę przedstawiono na wydruku modelu wirtualnego (rys. 5.). W korpusie wykona- 


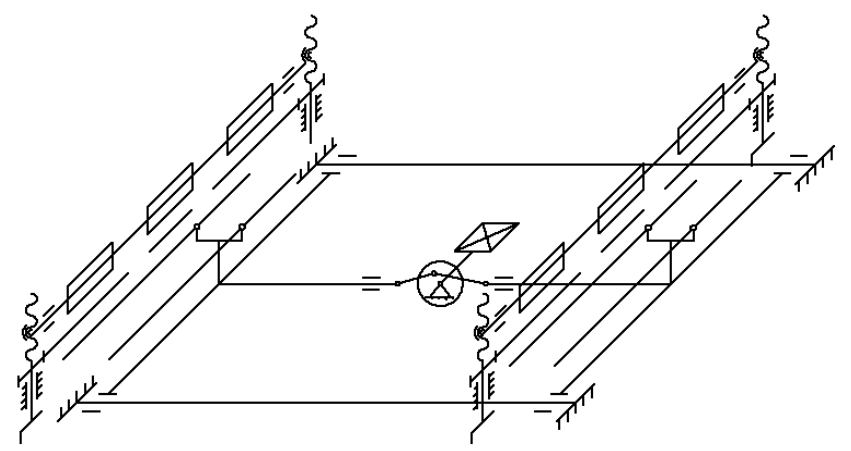

Rys. 4. Schemat kinematyczny układu napędowego

Fig. 4. Kinematic diagram of the drive unit

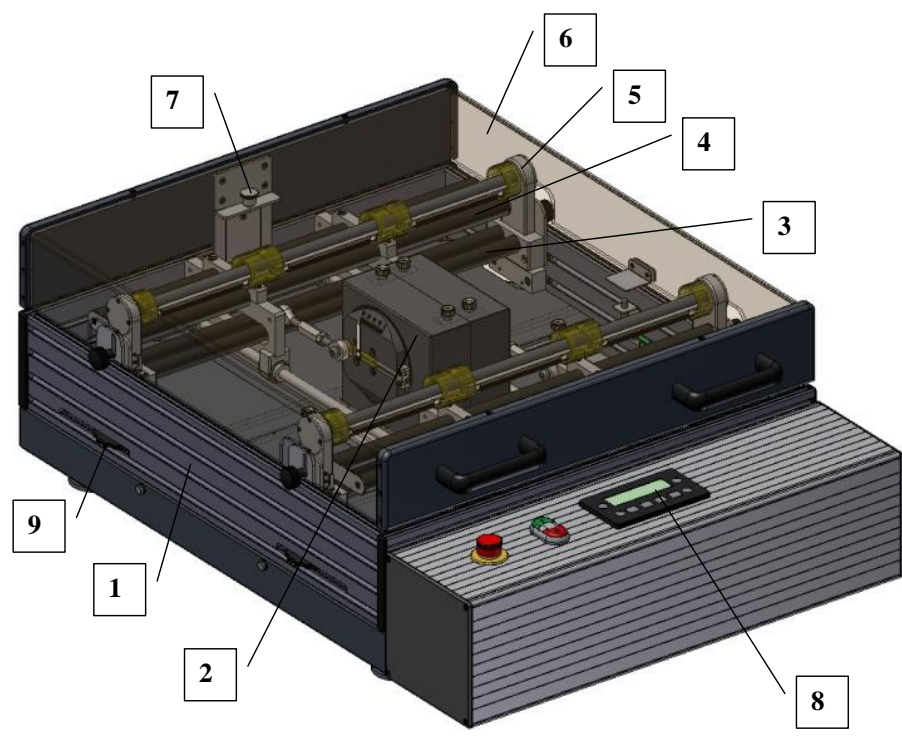

Rys. 5. Model urządzenia do badania odporności dokumentów na dwustronne zginanie: 1 - korpus, 2 - napęd ruchu posuwisto-zwrotnego rolek ruchomych, 3 - rolki stałe, 4 - rolki ruchome, 5 - uchwyty obrotowe dokumentów, 6 - osłona 7 - ogranicznik i blokada osłony 8 - moduł sterowania, 9 - pokrętło regulacji wysokości uchwytu

Fig. 5. Model of the test device for document endurance to two-sided bending: 1 - body, 2 - drive of the reciprocal motion of moveable rollers, 3 - permanent rollers, 4 - moveable rollers, 5 - document rotational grips, 6 - casing, 7 - limiter and casing blocking, 8 - control module, 9 - knob for grip height adjustment

nym z systemowych profili aluminiowych zostały wbudowane wszystkie moduły mechaniczne i sterujące pracą testera. $\mathrm{Z}$ centralnie umieszczonej przekładni 
ślimakowej motoreduktora napęd jest przenoszony na dwie symetrycznie osadzone na wale wyjściowym tarcze mimośrodowe, które poprzez korbowody wprawiają w ruch dwie sekcje rolek ruchomych (rys. 5.).

Napędzane przez motoreduktor tarcze mimośrodów mają naniesioną liniową skalę skoku rolek zginających. W wykonanym równolegle do skali rowku teowym znajduje się suwak, na którym jest ułożyskowany korbowód. Suwak ze wskaźnikiem jest przesuwany za pomocą śruby regulacyjnej (rys. 6.). Skala nacięta na tarczy mimośrodu służy do ustawienia wartości strzałki ugięcia dokumentu uzyskanej z pomiarów wykonanych za pomocą kalibratora. Obracające się tarcze mimośrodowe nadają określony skok w ruchu posuwisto-zwrotnym dwu sekcjom rolek ruchomych przesuwającym się po liniowych prowadnicach tocznych. Badane próbki są mocowane w uchwytach (5, rys. 5.), których położenie może być regulowane za pomocą pokręteł (9) odpowiednio do formatu dokumentu. Odległość odpowiadająca wymiarowi H2 (rys. 1.) jest ustawiana z wykorzystaniem skali naniesionej na korpus. Elektroniczny układ sterowania urządzenia składa się ze sterownika PLC, zasilacza sieciowego, przemiennika częstotliwości motoreduktora, interfejsu operatorskiego, czujników indukcyjnych i filtra przeciwzakłóceniowego. Oprogramowanie sterujące umożliwia komunikację sterownika PLC z operatorem poprzez terminal operatorski, informując o stanie urządzenia i wyświetlając na właściwych panelach komunikaty. Dotyczą one wyboru rodzaju wykonywanego testu, stanu zaawansowania lub zakończenia testu i możliwych do wprowadzenia nastaw. Prototypowy tester do dwustronnego zginania dokumentów został przedstawiony na rys. 7 .

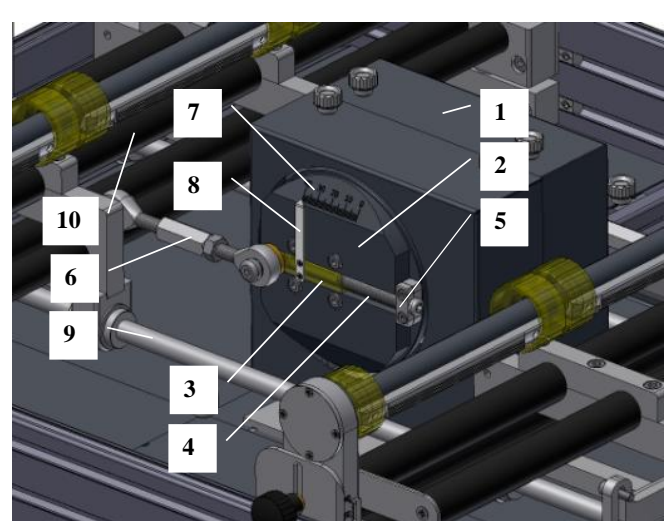

Rys. 6. Napęd oscylacyjny rolek zginających urządzenia do badania odporności dokumentów na zginanie: 1 - motoreduktor, 2 - tarcza mimośrodu, 3 - suwak mimośrodu, 4 - śruba suwaka mimośrodu, 5 - jarzmo śruby mimośrodu, 6 korbowód, 7 - skala nastawy skoku rolek, 8 - wskaźnik nastawy skoku, 9 - prowadnice liniowe, 10 - zespół rolek ruchomych

Fig. 6. Oscillatory drive of bending rollers of the test device for document endurance to two-sided bending: 1 - gear-motor, 2 eccentric disc, 3 - eccentric slide, 4 eccentric slide screw, 5 - eccentric screw yoke, 6 - connecting-rod, 7 - scale of roller stroke adjustment, 8 - stroke adjustment indicator, 9 - linear guides, 10 - unit of moveable rollers 


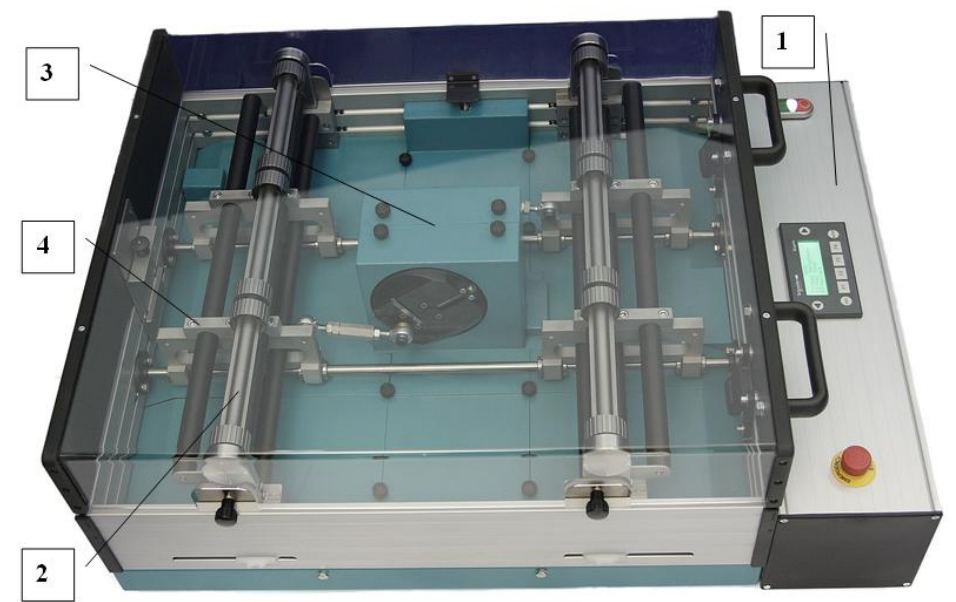

Rys. 7. Tester do badania odporności dokumentów na wielokrotne dwustronne zginanie: 1 - pulpit sterowniczy, 2 - moduł uchwytów obrotowych z mechanizmem regulacji wysokości, 3 - moduł napędu, 4 - moduł rolek ruchomych

Fig. 7. The tester for document endurance to repeated two-sided bending: 1 - control panel, 2 - module of roller grips with a height adjustment mechanism, 3 - drive module, 4 - module of moveable rollers

\section{Badania dokumentów z zastosowaniem systemu}

Realizację testu rozpoczyna się od wyznaczenia wartości strzałki ugięcia badanej próbki za pomocą modułu kalibracyjnego (rys. 8.). Następnie przeprowadza się regulację skoku rolek zginających testera na wartości uzyskane z pomiarów za pomocą kalibratora. W tym celu są ustawiane i blokowane mimośrody w zespole napędowym. Następnie w uchwytach ustawionych na wymaganej wysokości odpowiednio do formatu próbki są mocowane badane dokumenty. Parametry te są ustawiane osobno dla dwóch grup po trzy dokumenty po lewej i prawej stronie urządzenia. Pozwala to na równoczesne badanie sześciu próbek z różnymi parametrami wymuszeń.

$\mathrm{Z}$ panelu sterującego wybiera się odpowiednią liczbę cykli obciążenia i uruchamia urządzenie. Zakończenie badania jest sygnalizowane dźwiękiem. Próbki poddane obciążeniom zginającym wyjmuje się z układu testującego i sprawdza wpływ symulowanych oddziaływań użytkowych na możliwość odczytu danych, wytrzymałość i kształt dokumentu oraz inne cechy fizyczne. Zgodnie z wymaganiami ICAO [5] w paszporcie poddanym 1000 cykli zginania układ RFID powinien pozostać sprawny i pozwalać na odczyt danych zawartych w jego pamięci. Nie powinny występować obszary delaminacji elementów wielowarstwowych ani jakiekolwiek uszkodzenia strony zawierającej dane personalne przeznaczone do zautomatyzowanego odczytu. 


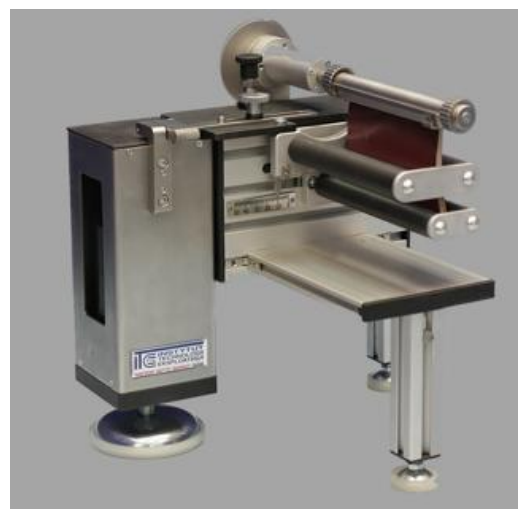

Rys. 8. Wyznaczenie wartości strzałki ugięcia badanej próbki

Fig. 8. Determination of tested sample deflection value

Urządzenia wchodzące w skład systemu testowania odporności dokumentów na dwustronne zginanie zostały zaprojektowane i wykonane w sposób zapewniający możliwość elastycznej regulacji parametrów realizowanych testów. Badane próbki mogą osiagać wymiary do formatu ID-3 włącznie $(125 \times 88 \mathrm{~mm})$ i grubość do $8 \mathrm{~mm}$. Mogą być zmieniane parametry kinematyczne testu, takie jak wartość odkształcenia próbki i jego lokalizacja oraz częstotliwość i liczba cykli obciążeń. Moduł kalibracyjny pozwala na badania odkształcenia dokumentu pod działaniem różnych obciążeń. Umożliwia to wykorzystanie systemu do badań odporności na deformacje charakterystyczne dla warunków użytkowych wielu wyrobów i komponentów różniących się między sobą sztywnością, wytrzymałością i rozmiarami.

\section{Podsumowanie}

Postęp w dziedzinie doskonalenia zabezpieczeń dokumentów podróży, identyfikatorów, kart płatniczych i innych wysoko zabezpieczonych dokumentów polega m.in. na instalowaniu w nich coraz doskonalszych i bardziej zaawansowanych układów elektronicznych RFID. Rozwiązania tego rodzaju dzięki coraz większej pamięci wewnętrznej stanowią doskonałe zabezpieczenie i dodatkowy nośnik informacji wspomagający bezpieczeństwo ich wykorzystania. Oprócz funkcji zabezpieczającej dokumenty muszą charakteryzować się dużą odpornością na obciążenia mechaniczne wynikające $\mathrm{z}$ długotrwałego użytkowania. Opisany w pracy system testowania dokumentów na zginanie pozwala na badanie różnego rodzaju dokumentów pod względem odporności na najczęściej występujące wymuszenia użytkowe $\mathrm{z}$ dużymi możliwościami modelowania ich intensywności.

Wprowadzone $\mathrm{w}$ urządzeniach tworzących system regulacje parametrów przeprowadzanych testów pozwalają na wykorzystanie ich do badania próbek dokumentów lub ich części składowych różnych typów, formatów, sztywności i konstrukcji. Metoda testowania odporności na dwustronne zginanie może być 
stosowana również do badania innych wyrobów poddawanych w trakcie użytkowania podobnym obciążeniom, np. różnego rodzaju połączeń klejonych, wyrobów wielowarstwowych, laminatów, powłok ochronnych.

Opracowane urządzenia są istotnym elementem składowym systemu przeznaczonego do prowadzenia prac rozwojowych i badań dokumentów zabezpieczonych elektronicznie tworzonego w ramach prac realizowanych w Instytucie Technologii Eksploatacji PIB w Radomiu, przeznaczonego do zastosowania w instytucjach zajmujących się opracowywaniem, wdrażaniem i wytwarzaniem tego rodzaju wyrobów.

\section{Literatura}

1. Neuby B.L., Rudin E.: Radio Frequency Identification: A panacea for governments? Public Organization Review, no 8 (2008), pp. 329-345.

2. Witschnig H., Merlin E.: About history, basics and applications of RFID technology. Elektrotechnik und Informationstechnik, nr 123, 3 (2006), s. 61-71.

3. RFID Smart Labels - A 'how to' guide to manufacturing and performance for the label converter. Tarsus E\&L Publication, London 2007.

4. Doc. 9303 Machine Readable Travel Documents. ICAO Sixth Edition 2006.

5. Machine Readable Travel Documents. Technical Report: Durability of Machine Readable Passports Version 3.2, ICAO 2006.

6. Kozioł S., Zbrowski A., Samborski T., Wiejak J.: Koncepcja systemu testowania połączeń montażowych $\mathrm{w}$ dokumentach $\mathrm{z}$ zabezpieczeniem elektronicznym. Technologia i Automatyzacja Montażu, nr 4 (2010), s. 6-9.

Praca naukowa wykonana $w$ ramach realizacji Projektu Badawczego Rozwojowego $\mathrm{nr}$ OR00003909 pn. „System i pilotowa implementacja zabezpieczeń elektronicznych zawierajacych uktady RFID”.

\section{THE SYSTEM FOR TESTING DOCUMENT ENDURANCE TO TWO-SIDED BENDING}

\footnotetext{
A bstract

The system is intended for endurance tests for electronically tagged documents (with RFID inlets) to repeated two-sided bending, which are executed with the use of the ICAO method. As a result of tests, an increased fatigue wear, particularly in the area around the RFID tag, can be observed.

The tests are carried out with the use of two devices: a calibrating device for the determination of a document deflection value at the load of $40 \mathrm{~N}$, and a tester for the execution of a given number of bending cycles. Both devices are equipped with a deflection value determination system, a deflection adjustment system, and a programmable cycle meter. One of the edges of the tested document is inserted into the roller grip, while the opposite edge is placed between support rollers. The bending rollers move both ways and as a result the document bends. The plan of the ICAO tests expects 1000 cycles of two-sided bending to be performed before the efficiency of the RFID inlet is verified. The system makes the testing of documents of different size possible, as it
} 
allows for the change in geometrical and dynamic parameters of the testing devices, which can be adjusted to different document sizes, structures, and a different RFID inlet placement. The aforementioned test method can also be used in tests of different products, which are subject to twosided bending during their operation, i.e.: glued joints, multilayered products, laminates or protective coatings.

Keywords: RFID, document durability, two-sided bending, endurance tests, passport

DOI: $10.7862 / \mathrm{rm} .2013 .3$

Otrzymano/received: 25.02 .2013

Zaakceptowano/accepted: 2.04 .2013 